\title{
Knowledge Mapping of Stakeholder Relationship Research in Construction Project - A Visual Analysis Using CiteSpace
}

\author{
Yang Yingnan", Yuan Lin, Zhang Yidan, Ma Yuandong
}

Department of Construction Management, Zhejiang University, 866 Yuhangtang Rd, Hangzhou, China

Keywords: Construction projects, stakeholder relationship, CiteSpace, cluster analysis.

\begin{abstract}
The last decade has witnessed rapid development in the literature on stakeholder relationship, however, there have been few attempts to map the research in this domain. To identify the trends in stakeholder relationship research, CiteSpace, a tool for visualizing patterns and trends in scientific literature, was used. Papers were selected from 18 authoritative journals via the core of Web of Science. The aim of this paper is to draw up the knowledge mapping of stakeholder relationship research, reflect the research focus and hot topics of this domain, show the evolution of the knowledge structure and detect emerging trends. We present all research focuses in a scientometric way and arrive at the following findings. First, five clusters were derived from the cocited references network of stakeholder relationship, including stakeholder concern, BIM, 4D CAD, Hydropower Engineering and Review. Second, the existing research of stakeholder relationship focus primarily on the factors that impact the stakeholder relationship such as technology, management methods, laws, and how the stakeholder relationship such as conflict or cooperation impact the construction projects.
\end{abstract}

\section{Introduction}

Stakeholder relationship has a strong impact on the success of the construction project, and a good cooperative relationship is conducive to the success of the project ${ }^{[1]}$. In recent years, with the increasing of mega projects, infrastructure projects and other complex projects, the types of stakeholder relationship are more and more complex. There are problems such as poor information exchange and imperfect communication mechanism among stakeholders, which result in conflicts. Meanwhile, due to the lack of information exchange platform, project information cannot be transmitted among stakeholders in a timely, accurate and effective manner, which seriously affects the collaboration efficiency of them, then, ultimately affects the duration, cost and performance of the whole project.

At present, the study of stakeholder relationship is relatively scattered, so it is necessary to use a systematic and quantitative review to comprehensively review the literature, analyse the development process of stakeholder relationship research, and have a comprehensive understanding of stakeholder relationship in construction projects. The purpose of this study is as follows: (1) Analyse influential literature in the field of stakeholder relations of construction projects from 2000 to 2018 with the method of scientific measurement. (2)By analysing the co-cited literature network, we find the research status of stakeholder relationship in construction projects, and the current research hotspots are determined through cluster analysis. (3) Using cluster analysis to detect the research direction and emerging trends the research.

\section{Research Methodology}

\subsection{Paper retrieval}

According to requirements of CiteSpace on data sources, Web of Science (WOS) core database was selected as the search engine in this study ${ }^{[2]}$ : [TS = (stakeholders OR team OR partners OR participants) AND (relationship OR conflict OR communication OR cooperation OR partnership OR collaboration OR Interoperability)], and paper retrieval was conducted from 2000 to 2018. 
1,698,711 papers were preliminary obtained. Only journal papers were selected, conference papers, book reviews and other papers were deleted. Papers were required to be in English. Through this step of screening, 1037638 papers were retrieved. In order to ensure the selected papers have reference value, 18 journals with great influence in the field of civil engineering were selected, and the search scope was narrowed to those 18 journals. Through this step of screening, 3392 papers were retrieved. Then, through reading the title and abstract of the paper, manual screening was carried out to further remove papers that was not strongly related to the research topic, and finally 384 papers were obtained.

\subsection{Scientometric analysis}

After journal source analysis and cluster analysis, each cluster is subdivided based on the content of the article to determine status and hot topics of stakeholder relationship research.

\section{Result}

\subsection{Journal source analysis}

A total of 384 papers were published throughout the year (Figure 1). Since 2000, the annual number of papers published has an increasing trend. After 2010, the quantity increased significantly, reaching the maximum number of papers published in 2017. It indicates that the importance of stakeholder relationship research is increasing all over the world, which gradually attracts the attention of scholars. Probably due to the problem of database and manual screening, the number of published papers showed a declining trend since 2017. In conclusion, based on the general publication trend, it is expected that more papers will be published in the future.

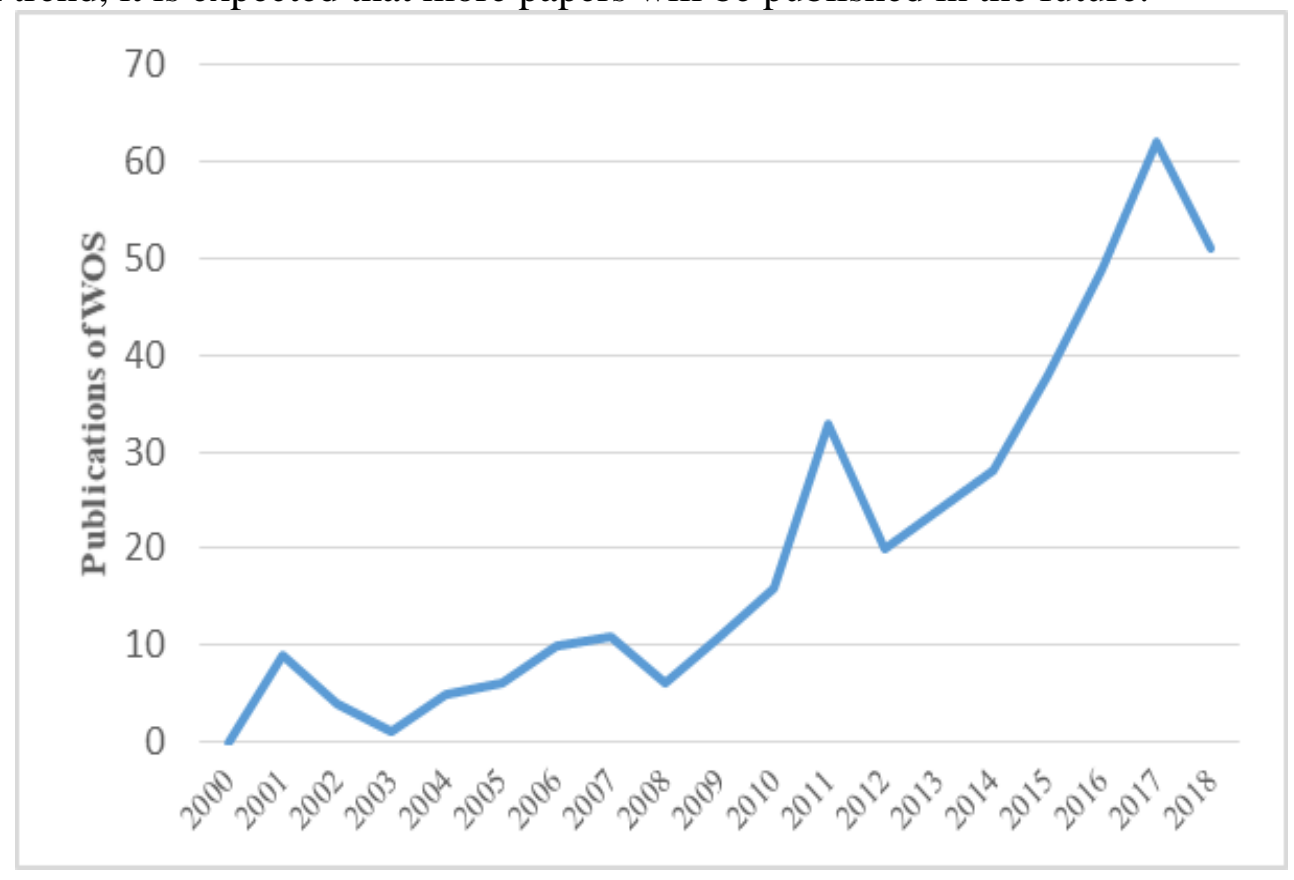

Figure 1 Number of publications per year.

The statistics of high-cited papers in the research topic of stakeholder relationship are shown in table 1. The articles such as Building Information Modelling Framework: A Research and Delivery Foundation for Industry Stakeholders (average of 32.82 citations per year), Exploring Critical Success Factors for Partnering in Construction Projects (average of 12.06 citations per year) and Building Environmental Assessment Methods: Redefining Intentions and Roles (average of 11 citations per year) with higher annual average citation. In terms of these papers, the hot topics are as follows: First, technology, BIM and management methods. Second, factors such as sustainable development or green construction impact on the stakeholder relationship. Third, tapes of stakeholder relationship such as conflict or cooperation impact the construction project. 
Table 1 Statistics of high-cited papers.

\begin{tabular}{|c|c|c|c|}
\hline Title & Author & $\begin{array}{c}\text { Total } \\
\text { citations }\end{array}$ & $\begin{array}{c}\text { Average } \\
\text { citations }\end{array}$ \\
\hline $\begin{array}{c}\text { Building information modelling framework: A } \\
\text { research and delivery foundation for industry } \\
\text { stakeholders }\end{array}$ & Succar et al.(2009) & 361 & 32.82 \\
\hline $\begin{array}{c}\text { Exploring critical success factors for partnering in } \\
\text { construction projects }\end{array}$ & Chan et al. (2004) & 193 & 12.06 \\
\hline $\begin{array}{c}\text { Building environmental assessment methods: } \\
\text { redefining intentions and roles }\end{array}$ & Cole et al.(2005) & 165 & 11 \\
\hline $\begin{array}{c}\text { A theoretical framework of a BIM-based multi- } \\
\text { disciplinary collaboration platform }\end{array}$ & Singh et al.(2011) & 163 & 18.11 \\
\hline $\begin{array}{c}\text { Value proposition on interoperability of BIM and } \\
\text { collaborative working environments }\end{array}$ & Grilo et al.(2010) & 127 & 12.7 \\
\hline $\begin{array}{c}\text { Social network model of construction } \\
\text { al.(2008) }\end{array}$ & 121 & 10.08 \\
\hline $\begin{array}{c}\text { Understanding Construction Industry Experience } \\
\text { and Attitudes toward Integrated Project Delivery }\end{array}$ & Kent et al.(2010) & 103 & 10.3 \\
\hline $\begin{array}{c}\text { Requirements for building information modeling } \\
\text { based lean production management systems for } \\
\text { construction }\end{array}$ & Sacks et al.(2010) & 88 & 8.8 \\
\hline $\begin{array}{c}\text { Development of a wireless sensor network system } \\
\text { for suspension bridge health monitoring }\end{array}$ & Chae et al.(2012) & 82 & 10.25 \\
\hline $\begin{array}{c}\text { A service oriented framework for construction } \\
\text { supply chain integration }\end{array}$ & Cheng et al.(2010) & 74 & 7.4 \\
\hline
\end{tabular}

\subsection{Clusters of co-citation analysis}

Co-citation analysis is a statistical method used to analyze the knowledge structure, reveal the number and authority of references cited in published papers. Meanwhile, it can be used to visualize scientific research fields, detect emerging topics and predict future research directions. Set the minimum cluster as 10 in the CiteSpace, filter out the unrepresentative clusters, and then divide the co-cited network into five clusters (Figure 2) named Stakeholder Concern, BIM, 4D CAD, Hydropower Engineering and Review.

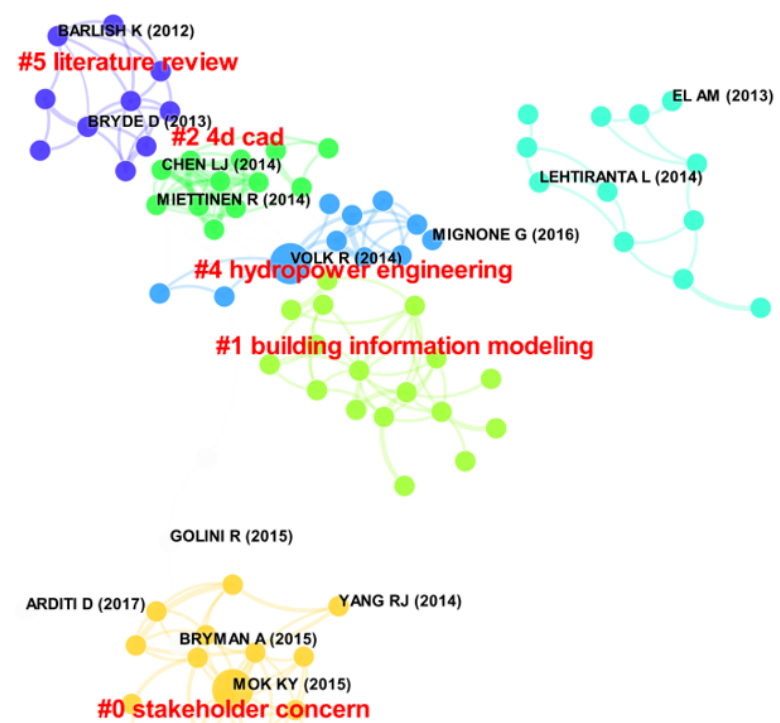

Figure 2 Co-citation clusters of Cited with the label of title, keywords and abstract. 


\section{Specific Analysis on Cluster\#0-\#4}

\subsection{Specific analysis on cluster \# 0 stakeholder concern}

Cluster \#0 is the largest cluster, which has 19 members. There are many research topics, including relationship management, risk, green building, sustainable development, innovation, and it has two high-cited literatures written by Mok, KY and Yang, RJ. Mok, KY ${ }^{[3]}$ believe that cultural differences will have an impact on the stakeholder relationship of mega projects, and so far there is no effective method to manage the stakeholder relationship. Yang, $\mathrm{RJ}^{[4]}$ concerns the risk of green building project, they developed a stakeholders associated risk analysis based on social network analysis method to evaluate project risks and its interaction, meanwhile, to improve the ability of stakeholders to assess risks.

In recent years, building energy conservation, green building, sustainable development and innovation have gradually become the focus of stakeholders. Some conflicts among stakeholders are caused by the inconsistency of building energy conservation and sustainable development goals ${ }^{[5]}$. Yik, FWH ${ }^{[6]}$ developed a new building energy conservation contract which can effectively promote cooperation among stakeholders. Meanwhile, it is necessary to develop strategies such as enhanced communication to promote stakeholder collaboration ${ }^{[7]}$. Multi-disciplinary collaboration is needed if projects have sustainable development objectives. It is necessary to determine the key role of sustainable building design, and to coordinate various majors with methods such as BIM to achieve knowledge sharing ${ }^{[8]}$. Whyte, $\mathrm{J}^{[9]}$ combined social and political factors to further analyze the motivation and innovation of stakeholders to promote better cooperation among stakeholders. Risks, benefits and interest also have an impact on stakeholder relationship. In the procurement stage, Eriksson, PE ${ }^{[10]}$ proposed a theoretical framework to explain how owners' purchasing behavior affects their relationship with contractors. In addition, the way of risk allocation will also affect the cooperation between the owner and the contractor, which can be reduced by means of risk premium ${ }^{[11]}$. Chan, APC ${ }^{[12]}$ found that the expectation of external stakeholders (government, public and affected communities, etc.) can promote the social benefits of the project, so a more comprehensive list of stakeholder expectations has been drawn up to manage the expectations of external stakeholders; For multinational companies or cross-professional teams should pay more attention to common goals, equal status and integrated management ${ }^{[13]}$.

\subsection{Specific analysis on cluster \# 1 BIM (building information modeling)}

Cluster \#1 is also the biggest cluster with many literatures, which is composed of 19 literatures. This cluster mainly studies the impact of BIM on stakeholder relationship, such as the impact of using BIM on project performance and the way of information exchange at each stage of the project, etc.

The use of BIM will bring a series of impacts on the project. Badi, $\mathrm{S}^{[14]}$ believe that using BIM can effectively improve the stakeholders' communication quality; Poirier EA ${ }^{[15]}$ concluded that BIM would prove the information exchange of stakeholders, thus effectively promote their collaboration then reduce waste and project costs ${ }^{[16]}$. Zheng, $\mathrm{L}^{[17]}$ put forward a benefit sharing model which can determine the common interests among stakeholders to promote the cooperation among them. Minho, $\mathrm{O}^{[18]}$ developed an integrated system that enables stakeholders to exchange information efficiently. Meanwhile, Ma, $\mathrm{Z}^{[19]}$ developed a collaboration model to enhance stakeholder cooperation in quality inspection process. Moreover, environmental sustainability is often seen as an integral part of design and often requires the collaboration of multiple professional designers.

\subsection{Specific analysis on cluster \# 2 4D CAD}

Cluster \#2 is composed of 12 literatures, which studies the impact of the application of 4D CAD and $4 \mathrm{D}$ BIM in the project on stakeholders. In addition to general projects, it also involves the mega and green building projects. There are many research topics, including conflict, information interaction, communication and coordination, etc. The most representative papers among that are

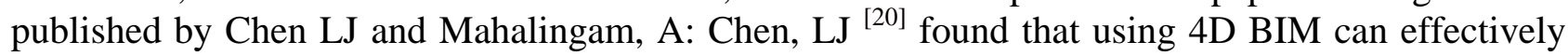


reduce stakeholder conflicts in the construction process through data analysis and model construction, and proved that using 4D BIM can effectively improve project quality. Mahalingam, $\mathrm{A}^{[21]}$ found the obstacles of 4D CAD in the practical application of the project through interviews, and elaborated the software development goals of 4D CAD in the future.

4D model can realize information integration and sharing among stakeholders to improve the communication efficiency ${ }^{[22]}$. But there are a series of problems, such as data format inconsistency, software incompatibility and information delay ${ }^{[23]}$. In addition, 4D CAD can effectively predict conflicts of task delivery by stakeholders ${ }^{[24]}$. It is benefit to different stakeholders coordinate with each other and control the project progress. On that basis, Scholtenhuis, LLO ${ }^{[25]}$ proposed a method based on 4D CAD to coordinate the work among stakeholders of underground public projects. Using 4D CAD to identify and predict conflicts during project delivery can effectively reduce the risk of project delay. Furthermore, Ding, $\mathrm{LY}^{[26]}$ developed $\mathrm{nD}$ system to provide a new platform for information exchange. The $\mathrm{nD}$ system can be used to integrate the latest information of all aspects, so that necessary information can be easily obtained and comprehensive decisions can be made for the owners.

\subsection{Specific analysis on cluster \# 3 hydropower engineering}

Cluster \#3 is composed of 11 literatures, which studies how to promote the success of infrastructure projects, hydropower Engineering projects, PPP projects and EPC projects by adjusting the stakeholder relationship. There are many research topics in this cluster such as stakeholders information sharing, communication, government, trust and contract.

According to research, information exchange and integration of stakeholders will have a great impact on infrastructure projects. Their communication and collaboration can effectively prevent project delays ${ }^{[27]}$. Software needs to be developed to achieve integrated management of lifecycle information ${ }^{[28]}$. In addition, sustainable development goals need to be achieved in the decision stage of infrastructure projects. A new decision model is developed to guide owners' decisions and maximize the environmental and economic benefits of stakeholders ${ }^{[29]}$. Trust is one of the factors that affect the stakeholder relationship, and it is also the basis of using BIM. Lee, CY ${ }^{[30]}$ proposed a trust-based EPC project contract model to improve the use efficiency of BIM by improving mutual trust between stakeholders. Effah EA ${ }^{[31]}$ developed a fuzzy comprehensive evaluation model to evaluate the success of PPP water supply projects. Furthermore, a sound legal system is conducive to promoting stakeholder relationship in PPP projects, and the government should play a leading role in promoting reasonable risk distribution ${ }^{[32]}$.

\subsection{Specific analysis on cluster \# 4 review}

\#4 consists of 10 literatures. The literatures of this cluster are systematically studied on stakeholder relationship through literature review or a large number of case studies. There are many research topics in this cluster: BIM, information communication technology (ICT), integrated project delivery (IPD), sustainable development, etc., and it has two high-cited literatures written by Bryde, D and Barlis. Using BIM can enhance the information interaction among stakeholders, thus effectively reducing the project costs and shortening the construction period. However, the difficulty of using BIM technology hinders its large-scale application ${ }^{[33]}$. Barlish, $\mathrm{K}^{[34]}$ developed a more complete method to analyze the benefits brought by BIM to the project and established the calculation model of BIM value assessment. Other scholars have studied the research of BIM, it is found that there are many problems in BIM technology. Firstly, the application cost of BIM is too high to popularize BIM in the construction industry in North America. So it is needed to reduce the

application cost of BIM ${ }^{[35]}$. Secondly, it is necessary to carry out deep development of the BIM software to realize real-time information exchange [36], so as to facilitate stakeholder communication. Chung, JKH ${ }^{[37]}$ reviewed the development of information communication technology (ICT), meanwhile, they come up with an innovative collaborative approach which can improve stakeholder engagement. Kent, DC ${ }^{[38]}$ believed that trust, respect and good team relationship are the key to the success of IPD projects, BIM or advanced information technology application is not a prerequisite for IPD. Stakeholders have different perceptions of the key to 
project success ${ }^{[39]}$, the ineffective communication or an inconsistent goal may lead to the delay of the project ${ }^{[40]}$. In addition, 41 indicators are determined to judge the quality of PPP projects and improve project performance management ${ }^{[41]}$. Through literature reading, it is found that the recent project management literature define the process of project construction as a process of value cocreation. Therefore, the establishment of a knowledge and information sharing platform for owners and other stakeholders can effectively improve the degree of stakeholders' participation in the project and thus promoting the success of the project ${ }^{[42]}$.

\section{Conclusion}

The research on the stakeholder relationship of construction engineering projects has been continuing. The research shows that the stakeholder relationship will have a greater impact on the success of the project, so how to promote the good cooperation of stakeholders is an enduring research topic. Through the summary of the research results, it is concluded that the main factors affecting the stakeholder relationship are: Firstly, conflicts of interest, goals and expectations of stakeholders. Secondly, various reasons (such as software problems, cultural differences) caused by the lack of information exchange. Thirdly, the impact of changes in policy requirements (such as green building, sustainable development), industry development (EPC, PPP, IPD and other modes) and other factors on stakeholders (such as risk allocation and trust issues). Future research can start from the factors that affect the relationship between stakeholders, or improve stakeholder relationship: Firstly, stakeholder concerns under new policies, new environment or different procurement methods can be analyzed. Meanwhile, the expectations and objectives of stakeholders are analyzed to reduce conflicts among all parties. Secondly, further development of BIM software to enhance communication and information exchange among stakeholders. Thirdly, how to improve relevant laws and contracts of different procurement modes should be analyzed in the future.

\section{References}

[1] Oppoing G, Chan A, Dansoh A. (2017) A Review of Stakeholder Management Performance Attributes in Construction Projects. International Journal of Project Management. 35, 1037-1051.

[2] Chen C. (2006) CiteSpace II:Detecting and Visualizing Emerging Trends and Transient Patterns in Scientific Literature. Journal of the American Society for Information Science and Technology. 3, 359-377.

[3] Mok K, Shen G, Yang Q. (2015) Stakeholder Management Studies in Mega Construction Projects: A Review and Future Directions. International Journal of Project Management. 33, 446457.

[4] Yang R, Zou P. (2014) Stakeholder-Associated Risks and Their Interactions in Complex Green Building Projects: A Social Network Model. Building and Environment. 73, 208-222.

[5] Feige A, Wallbaumand H. (2011) Harnessing Stakeholder Motivation: Towards a Swiss Sustainable Building Sector. Building Research and Information. 39,504-517.

[6] Yik F, Lee L. (2004) Partnership in Building Energy Performance Contracting. Building Research and Information. 32, 235-243.

[7] Liu J, Low S, Yang J. (2013) Conceptual Framework for Assessing the Impact of Green Practices on Collaborative Work in China's Construction Industry. Journal of Professional Issues in Engineering Education and Practice. 139, 248-255.

[8] Zanni M, Soetanto R, Ruikar K. (2017) Towards a BIM-enabled Sustainable Building Design Process: Roles, Responsibilities, and Requirements. Architectural Engineering and Design Management. 13, 29.

[9] Whyte J, Sexton M. (2011) Motivations for Innovation in the Built Environment: New 
Directions for Research. Building Research and Information. 39, 473-482.

[10] Eriksson P. (2008) Procurement Effects on Coopetition in Client-contractor Relationships. Journal of Construction Engineering and Management. 134, 103-111.

[11] Zhang S, Zhang S, Gao Y. (2016) Contractual Governance: Effects of Risk Allocation on Contractors' Cooperative Behaviour in Construction Projects. Journal of Construction Engineering and Management. 142, 112-114.

[12] Chan A, Oppong G. (2017) Managing the Expectations of External Stakeholders in Construction Projects. Engineering, Construction and Architectural Management. 24, 736-756.

[13] Anvuur A, Kumaraswamy M, Effects M. (2015) Effects of Teamwork Climate on Cooperation in Cross Functional Temporary Multi-Organization Workgroups. Journal of Construction Engineering and Management. 142, 112-114.

[14] Badi S, Diamantidou D. (2017) A Social Network Perspective of Building Information Modelling in Greek Construction Projects. Architectural Engineering and Design Management. 13, $1-17$.

[15] Poirier E, Forgues D, Staub-French S. (2017) Understanding the Impact of BIM on Collaboration: a Canadian Case Study. Building Research and Information. 45, 1-15.

[16] Zhang X, Azhar S, Nadeem A. (2015) Using Building Information Modelling to Achieve Lean Principles by Improving Efficiency of Work Teams. International Journal of Construction Management. 18, 293-300.

[17] Zheng L, Lu W, Chen K. (2017) Benefit Sharing for BIM Implementation: Tackling the Moral Hazard Dilemma in Inter-firm Cooperation. International Journal of Project Management. 35, 393-405.

[18] Minho O, Jaewook L, Seung W. (2015) Integrated System for BIM-based Collaborative Design. Automation in Construction. 58, 196-206.

[19] Ma Z, Cai S, Mao N. (2018) Construction Quality Management Based on a Collaborative System Using BIM and Indoor Positioning. Automation in Construction. 92, 35-45.

[20] Chen L J L H A B. (2014) A BIM-based Construction Quality Management Model and Its Applications. Automation in Construction. 2, 64-73.

[21] Mahalingam A, Kashyap R, Mahajan C. (2009) An Evaluation of the Applicability of 4D CAD on Construction Projects. Automation in Construction. 19, 148-159.

[22] Hartmann T, Fischer M. (2007) Supporting the Constructability Review with 3D/4D Models. Building Research and Information. 35, 70-80.

[23] Park J, Cai H, Dunston P. (2017) Database-Supported and Web-Based Visualization for Daily 4D BIM. Journal of Construction Engineering and Management. 143, 24-30.

[24] Trebbe M, Hartmann T, André D. (2015) 4D CAD Models to Support the Coordination of Construction Activities Between Contractors. Automation in Construction. 49, 83-91.

[25] Scholtenhuis L, Hartmann T, Doree A. (2016) Testing the Value of 4D Visualizations for Enhancing Mindfulness in Utility Reconstruction Works. Journal of Construction Engineering and Management. 142, 78-82.

[26] Ding L, Zhou Y, Luo H. (2012) Using nD Technology to Develop an Integrated Construction Management System for City Rail Transit Construction. Automation in Construction. 21, 64-73.

[27] Bubshait A, Siddiqui M, Albuali A. (2015) The Role of Communication and Coordination in Project Success: A Case Study. Journal of Performance of Constructed Facilities. 29, 36-41.

[28] Halfawy M, Vanier D, Froese T. (2006) Standard Data Models for Interoperability of 
Municipal Infrastructure Asset Management Systems. Canadian Journal of Civil Engineering. 33, 1459-1469.

[29] Mostafa M, El-Gohary N. (2014) Stakeholder-Sensitive Social Welfare-Oriented Benefit Analysis for Sustainable Infrastructure Project Development. Journal of Construction Engineering and Management. 140, 1-12.

[30] Lee C, Chong H, Wang X. (2018) Enhancing BIM Performance in EPC Projects through Integrative Trust-Based Functional Contracting Model. Journal of Construction Engineering and Management. 144, 1-12.

[31] Effah E, Chan A. (2016) Critical Success Factors for Public-private Partnership in Water Supply Projects. Facilities. 34, 124-160.

[32] Wang Y. (2015) Evolution of Public-private Partnership Models in American Toll Road Development: Learning Based on Public Institutions' Risk Management. International Journal of Project Management. 33, 684-696.

[33] Bryde D, Broquetas, Martí. (2013) The Project Benefits of Building Information Modelling (BIM). International Journal of Project Management. 31, 971-980.

[34] Barlish K, Sullivan K. (2012) How to Measure the Benefits of BIM - A Case Study Approach. Automation in Construction. 24, 149-159.

[35] Hanna A, Yeutter M, Aoun D. (2014) State of Practice of Building Information Modelling in the Electrical Construction Industry. Journal of Construction Engineering and Management. 140, 815-825.

[36] Chen K, Lu W, Peng Y. (2015) Bridging BIM and Building: From a Literature Review to an Integrated Conceptual Framework. 33, 1405-1416.

[37] Chung J, Kumaraswamy M, Palaneeswaran E. (2009) Improving Megaproject Briefing Through Enhanced Collaboration with ICT. Automation in Construction. 18, 966-974.

[38] Kent D, Becerik-Gerber B. (2010) Understanding Construction Industry Experience and Attitudes toward Integrated Project Delivery. Journal of Construction Engineering and Management. 136, 815-825.

[39] Davis K. (2014) Different Stakeholder Groups and Their Perceptions of Project Success. International Journal of Project Management. 32, 189-201.

[40] Doloi H, Sawhney A, Iyer K. (2012) Analysing Factors Affecting Delays in Indian Construction Projects. International Journal of Project Management. 30, 479-489.

[41] Yuan J, Wang C, Skibniewski M.J. (2012) Developing Key Performance Indicators for PublicPrivate Partnership Projects: Questionnaire Survey and Analysis. Journal of Management in Engineering. 28, 252-264.

[42] Chang A, Chih Y, Chew E. (2013) Reconceptualising Mega Project Success in Australian Defence: Recognising the Importance of Value Co-creation. International Journal of Project Management. 31, 1139-1153. 